\title{
Check list para a elaboração e análise de questionários em
}

\author{
pesquisas de crenças
}

\author{
Maria Tereza Nunes Marchesan* \\ André Gonçalves Ramos
}

\begin{abstract}
Resumo: A pesquisa sobre crenças tem no questionário um instrumento importante de coleta de dados, pois as discussões sobre crenças são feitas, geralmente, a partir das respostas obtidas por esse meio. Dessa forma, quanto mais bem elaborado o questionário, tanto mais válidas serão as respostas e mais confiável será a discussão. Levando essa afirmação em consideração, com o fim de elaborar questionários para pesquisar crenças de professores e alunos sobre o ensinoaprendizagem de espanhol na escola, procedeu-se a uma revisão sobre pesquisa qualitativa e o uso de questionários. Como resultado dessa revisão, foi criado um check list como instrumento auxiliar para a elaboração e análise de questionários para pesquisas em crenças. Esse instrumento prevê tópicos a serem considerados na criação e apresentação de questões e questionários. Porém, essa proposta, embora tenha se mostrado eficiente para a elaboração dos questionários da pesquisa que lhe deu origem, tem um caráter experimental podendo, ainda, sofrer ajustes.
\end{abstract}

Palavras-chave: Crenças; Metodologia da Pesquisa; Questionários; Check List.

Resumen: La investigación sobre creencias encuentra en el cuestionario un importante instrumento para recoger datos, pues las discusiones sobre creencias son en general desarrolladas a partir de las respuestas obtenidas por ese medio. Por tanto, cuánto más bien elaborado el cuestionario, tanto más válidas serán las respuestas y más confiable será la discusión. Considerando eso, con el objetivo de elaborar cuestionarios para investigar creencias de profesores y alumnos sobre el proceso de enseñanza y aprendizaje de español en escuelas, se llevó a cabo una revisión sobre investigación cualitativa y uso de cuestionarios. Como resultado de esa revisión, se ha creado un check list como instrumento de apoyo para la elaboración y análisis de cuestionarios para investigaciones de creencias. Este instrumento prevé tópicos a ser considerados en la creación y presentación de cuestiones y cuestionarios. Sin embargo esta propuesta, aunque haya sido eficiente para la elaboración de los cuestionarios de la investigación que la originó, tiene un carácter experimental y puede aun ser ajustada.

Palabras-clave: Creencias; Metodología de la Investigación; Cuestionarios; Check List.

\section{Introdução}

Este trabalho tem origem no projeto de pesquisa desenvolvido pelo Centro de Ensino e Pesquisa de Línguas Estrangeiras Instrumentais (CEPESLI/UFSM) intitulado Encontros e Desencontros entre Crenças sobre Aprendizagem e Avaliação de Professores e de seus Alunos de LE. O objetivo principal do projeto é descobrir quais

\footnotetext{
* Professora do Departamento de Letras Estrangeiras Modernas da UFSM.

Mestrando do Curso do Pós-Graduação em Letras/Estudos Linguísticos da UFSM.
} 
são as crenças de professores e de seus alunos em relação à aprendizagem e avaliação em LE e, num segundo momento, estudar as relações de concordância e discordância entre elas. Esta pesquisa coletou informações de dois professores e quatro turmas de alunos de espanhol do ensino básico de escolas públicas situadas no bairro Camobi em Santa Maria-RS.

A metodologia utilizada está baseada na abordagem metacognitiva, descrita em Barcelos (2001), em que as crenças são inferidas a partir de entrevistas semiestruturadas, auto-relatos e questionários semi-estruturados. Nesta abordagem, o conhecimento cognitivo, ainda que nem sempre empiricamente sustentável, é considerado como conhecimento estável e declarável. O pressuposto é que os sujeitos pensam sobre seu próprio processo de aprendizagem e, por isso, são capazes de articular verbalmente suas crenças. Dessa forma, compreende-se possível coletar os dados através de entrevistas e questionários. Esta metodologia permite que se reflita sobre os dados no decorrer da coleta e da análise dos mesmos. Assim, as hipóteses não são elaboradas previamente, mas sim, em um processo interativo em que estas vão se originando na medida em que se aprofunda a análise. Esse processo metodológico é contínuo ao longo da pesquisa, o que pode causar a necessidade de se buscar mais dados ou novas teorias que ajudem a formulação de novas hipóteses e conclusões. Uma das vantagens desse tipo de análise decorre do reconhecimento das crenças como parte do processo de raciocínio. Assim, através dos questionários e entrevistas, os sujeitos da pesquisa podem definir e avaliar o processo de aprendizagem em seus próprios termos (BARCELOS, 2001).

Diante disso, uma das primeiras atitudes tomadas para dar andamento ao desenvolvimento do projeto foi a criação de dois questionários desenvolvidos exclusivamente para mapear crenças de professores e alunos sobre aprendizagem e avaliação em LE. No entanto, para desenvolver os questionários de pesquisa, verificouse a necessidade de aprofundar o estudo sobre o tema elaboração de questionários para que o resultado trouxesse dados confiáveis e válidos e, ao mesmo tempo, uma maior facilidade para análise das respostas. Na verdade, aprendemos com a experiência prática o que as palavras de Hair Jr. et. al. (2005, p. 212) resumem bem: "muitos indivíduos acreditam que os questionários são fáceis de criar. Mas quem passa pela experiência de criar um sabe que isso não é verdade". Cabe ressaltar que na bibliografia consultada 
para orientar a formulação do questionário consta uma obra voltada para pesquisa em Administração - Fundamentos de Métodos de Pesquisa em Administração - (HAIR JR et. al. 2005). Apesar disso, as considerações nela contidas resultam em preciosas instruções para pesquisas qualitativas em geral e, também para a área de estudos de crenças sobre ensino. Isso é notadamente verdadeiro na medida em que na pesquisa em administração também se busca informações acerca de "atitudes, crenças, opiniões, comportamentos, etc.” (HAIR JR et. al. 2005, p. 152).

Como resultado do estudo bibliográfico sobre o tema, foi criado um check list como instrumento auxiliar para a elaboração e análise dos questionários necessários para o desenvolvimento da pesquisa. Assim, este artigo objetiva apresentar esse instrumento e discutir sobre a importância de cada tópico a ser considerado na criação e apresentação de questões e questionários. Porém, primeiro, julgamos relevante discutir brevemente sobre o que é e para que serve um questionário.

\section{Questionário}

O que é? Para que serve?

É de conhecimento comum dentro da Linguística Aplicada que a pesquisa sobre crenças é relativamente recente. Conforme Barcelos (2004), os primeiros trabalhos surgiram no exterior nos anos oitenta com os trabalhos de Horwitz em 1985 e Wenden em 1986 e 1987 e, no Brasil, na década de noventa, com os trabalhos de Leffa de 1991, Almeida Filho de 1993 e Barcelos de 1995. Atualmente esta área parece estar consolidada no campo da Linguística Aplicada (BARCELOS, 2006; 2007). Silva (2010) apresenta um retrato atual da área de crenças no ensino-aprendizagem de línguas, abordando diversos aspectos concernentes à pesquisa em crenças na Linguística Aplicada.

No que diz respeito às abordagens de pesquisa, Barcelos (2001) apresenta uma revisão das metodologias de estudo de crenças sobre aprendizagem de línguas que vêm sendo utilizadas durante esse período e sustenta que (embora estudiosos apontem algumas desvantagens) os "questionários têm sido largamente utilizados na investigação das crenças e oferecem várias vantagens. Eles são menos ameaçadores que observações, 
são úteis se o pesquisador tem recursos limitados e pouco tempo" (BARCELOS, 2001 p. 78).

Questionários são instrumentos desenvolvidos para medir características importantes de indivíduos e para coletar dados que não estão prontamente disponíveis ou que não podem ser obtidos pela observação. Nesse sentido, Ludwig (2009) também alerta para que não se use os questionários para pedir informações existentes em outras fontes. Na mesma linha, encontramos a definição de Gil (1999, p. 128) que considera o questionário como uma "técnica de investigação composta por um número mais ou menos elevado de questões apresentadas por escrito às pessoas, tendo por objetivo o conhecimento de opiniões, crenças, sentimentos, interesses, expectativas, situações vivenciadas, etc.”. Esse tipo de instrumento é frequentemente respondido sem a presença do pesquisador e, por isso, supõe-se que o respondente tenha conhecimento e motivação para completá-los sozinho. Para que isso ocorra, "o conteúdo e o formato devem ser atraentes o suficiente para que os respondentes realmente preencham e devolvam o questionário" (HAIR JR et. al., 2005, p. 160). Porém, é justamente esse um dos problemas da aplicação de questionários: a perda de controle do pesquisador. É impossível, por exemplo, saber se o respondente pediu opinião de terceiros, se respondeu na sequência indicada, etc.

Geralmente empregados em pesquisas com abordagem qualitativa, os questionários são usados para coletar dados primários capazes de identificar os problemas de pesquisa que possam ajudar a formular estruturas conceituais. Isso quer dizer que esse tipo de pesquisa não se preocupa em buscar evidências que comprovem hipóteses previamente definidas, e sim, em formular teorias a partir da análise dos dados coletados. Lüdke denomina esse movimento de "processo indutivo" (LÜDKE, 1986, p. 13). Em resumo, a abordagem qualitativa se caracteriza por enfatizar mais o processo do que o produto, por investigar a "perspectiva dos participantes" sobre o tema proposto (LÜDKE, 1986, p. 12) e, por isso, geralmente envolve o uso de amostras menores ou estudos de caso. 


\section{Passos para criação e análise de questionários}

Como vimos, a aplicação de questionários é uma fase importante da pesquisa de abordagem qualitativa em geral e, particularmente, na pesquisa de crenças sobre ensino línguas. No entanto, para que o resultado seja composto por dados confiáveis e válidos, é necessário elaborá-los obedecendo a um processo sistemático.

O primeiro passo se refere à aspectos gerais como a definição dos objetivo do projeto e das questões de pesquisa. Isso implica no cuidado com a adequação das questões às características dos respondentes, isto é, ao criar questões o pesquisador deve avaliá-las do ponto de vista dos sujeitos da pesquisa. Para isso, pode-se levar em consideração aspectos como idade, escolaridade, classe social, experiências anteriores (sempre que for possível conhecê-las); julgar os sujeitos em termos de capacidade e disposição para responder, etc. Também é preciso observar se os sujeitos responderão com exatidão às questões. Para isso, deve-se cuidar para não criar perguntas muito extensas, ou muito difíceis; tomar cuidado para não induzir a respostas "politicamente corretas" ou a respostas que os respondentes interpretem como as que o pesquisador espera (questões dominantes), etc. (HAIR JR et. al. 2005).

O segundo passo refere-se ao esclarecimento do(s) conceito(s) envolvido(s) na pesquisa (crenças, por exemplo). Esse passo torna-se importante porque é(são) o(s) conceito(s) a ser(em) estudado(s) que vai(ão) orientar a definição do método de análise das respostas. O conceito estudado também é um dos fatores que determina os tipos de questões a serem elaboradas.

A tipologia do questionário é objeto do terceiro passo da elaboração de questionários e diz respeito à maneira como as perguntas são ordenadas, estruturadas e apresentadas.

Como as primeiras questões podem influenciar as respostas das seguintes, processo chamado de "efeitos de contexto" por Hair Jr et. al. (2005), a ordem das questões deve partir das mais gerais para as mais específicas. Para isso, é importante considerar os tipos de perguntas: abertas e fechadas. As questões de opinião abertas devem preceder às questões fechadas quando tratarem do mesmo tópico. Com isso, busca-se evitar que as alternativas da questão fechada interfiram na resposta da questão aberta. 
Vários autores tecem considerações sobre a divisão dos questionários em perguntas abertas e fechadas. Segundo Nunan (2003), as perguntas fechadas são aquelas em que a gama de respostas possíveis é determinada pelo pesquisador, enquanto que as questões abertas são aquelas em que o sujeito pesquisado é livre para decidir o que e como vai responder, isto é, o respondente é livre para usar suas próprias palavras. Para Hair Jr. et al (2005, p. 219), as questões abertas são utilizadas quando o pesquisador não conhece as possíveis respostas ou quando acredita que as alternativas podem influenciar as respostas. São relativamente fáceis de elaborar, porém, exigem muito tempo e esforço para entender as respostas. Para este autor, em questionários em que o próprio entrevistado preenche as respostas, as perguntas abertas devem ser usadas com "parcimônia" (p.219). Nas questões fechadas o entrevistado necessita escolher entre um número determinado de opções. Hair Jr. et al (2005, p. 160) afirma que as perguntas desse tipo devem apresentar "possibilidades de respostas (opções) mutuamente excludentes e limitadas a um número exaustivo de alternativas para cada resposta possível”. Para Ludwig (2009), esse tipo de questão exige mais tempo para elaborar que as abertas porque, sempre há dificuldade de elaborar opções de respostas precisas, porém, por outro lado, torna mais fácil analisar e tabular as respostas.

No que diz respeito à estrutura, esta deve apresentar três seções de perguntas. A primeira é composta por questôes de abertura. O objetivo delas é criar uma atmosfera que conduza à participação, estimulando no entrevistado o interesse pelo tema. Para isso, as questões de abertura devem ser simples, mas ainda assim relevantes para o estudo. Segundo Hair Jr et. al. (2005), costuma-se pedir para que o respondente expresse sua opinião sobre uma questão que provavelmente será considerada importante. Ludwig (2009), que as denomina itens de aquecimento, também propõe a inserção de questões em que o respondente possa fazer críticas, julgamentos e comentários. A segunda seção se compõe de perguntas relacionadas aos tópicos pesquisados. Segundo Hair Jr. et al (2005, p. 223), "essa série de perguntas normalmente trata de atitudes, crenças, opiniões, comportamentos, etc.”. As questões que pedem informações de natureza mais pessoal devem ser colocadas na última seção do questionário, pois, se feitas no início, podem afetar as respostas das questões subsequentes. 
A apresentação das questões também é de grande importância para um questionário. A forma como são colocadas deve almejar a obtenção de dados mais exatos e confiáveis. Para isso, a redação deve ser simples (adequada às características dos sujeitos - escolaridade principalmente), evitando termos que possam causar malentendidos. Também deve ser breve, porque "quanto mais longa for a pergunta, maior a probabilidade de ser mal compreendida pelos respondentes" (HAIR JR et. al. 2005, p. 225). O texto deve ser claro, conciso evitando-se palavras desconhecidas ou que podem ter mais de um significado, isto é, que possam ser consideradas ambíguas.

Deve-se tomar cuidado para não incluir dois ou mais tópicos por questão (questão múltipla), pois podem tornar difícil sua interpretação ou até impossível. Para Nunan (2003, p.143) as perguntas não devem pedir mais de uma resposta: “Questions should not be complex and confusing, nor should they ask more than one thing at a time". Encontramos um exemplo de frase confusa, por exemplo, em uma questão que peça para o respondente dizer se concorda ou não com as afirmações do tipo: "Meus alunos são dispostos e pontuais", ou "Os funcionários são cordiais e instruídos". Neste tipo de questão, não se pode saber a qual dos dois adjetivos a resposta se refere.

Outro fator importante na apresentação das questões que deve ser evitado é a chamada questão dominante. Como dissemos antes, não é muito difícil criar questões abertas, porém, é comum surgirem questões que implicitamente sugerem que uma determinada resposta é desejável, o que pode levar o respondente a adequar suas respostas. Neste sentido, Nunan (2003, p. 143) adverte que o pesquisador não pode revelar suas opiniões sobre as questões que está investigando: "it is particularly important that the researchers not reveal their own attitudes through leading questions such as the following: 'do you think that the concept of learner-centredness is utopian and unrealistic?".

Ainda sobre a apresentação, devemos considerar que o espaçamento e a organização das questões no questionário também podem afetar as respostas, principalmente quando o próprio respondente as preenche. A organização das questões diz respeito principalmente às instruções que devem introduzir questões que podem apresentar dificuldades de compreensão. Por isso, as instruções presentes num questionário devem ser suficientemente claras para: introduzir e explicar como responder; para indicar quantas respostas são aceitáveis; para indicar se os respondentes 
devem responder sozinhos, etc. Segundo Hair Jr. et al (2005, p. 229), “as instruções sempre devem ser claras, concisas e coerentes (formato padrão) ao longo de todo o questionário". Para obter bons resultados nessa tarefa é recomendado "apresentar as instruções em negrito, itálico ou maiúsculas para distingui-las das questões e aumentar a probabilidade de serem compreendidas facilmente" (HAIR JR. et al, 2005,p. 229). A extensão do questionário também deve receber atenção especial, visto que há resistência por parte dos entrevistados em preencher questionários muito longos (Ludwig, 2009).

O quarto passo diz respeito ao pré-teste, etapa pela qual, segundo Nunan (2003), todo questionário deve passar antes de ser aplicado. Para este autor,

(A) trap for the inexperienced researcher is to collect the data and then realise that the question was asked in a way which cannot be analysed to answer the question. Because of these and other pitfalls, it is imperative to pilot any questionnaire which is developed. (In fact, I would argue strongly that all research should have a piloting phase). (NUNAN, 2003, p. 145)

Através do pré-teste, o pesquisador pode avaliar a provável exatidão e coerência das respostas. Este deve ser aplicado utilizando-se uma amostra de respondentes com características semelhantes às dos futuros sujeitos. Seguindo a mesma linha, Hair Jr. et al (2005) agrega ainda que o pré-teste também deve ser aplicado em ambiente semelhante ao que será usado na pesquisa. Além disso, devem ser incluídas questões de sondagem sobre cada parte do questionário para garantir que não há problemas de clareza nas instruções e não apresenta dificuldades de interpretação. Por último, caso haja necessidade de mudanças mais significantes, o questionário deve ser novamente testado, sempre respeitando as instruções acima.

O quinto e último passo refere-se ao modo de aplicação do questionário. Segundo Hair Jr. et al (2005), há cinco modos principais de administrar um questionário: auto-administrado; por correspondência; através de meios eletrônicos; por entrevistas presenciais e por conversa online. Cada forma de aplicar apresenta uma melhor prática para aumentar a probabilidade de se obter respostas mais exatas. 


\section{Check List}

Tendo em vista as palavras de Hair Jr. et al (2005) “Quando uma lista inicial de questões de pesquisa é desenvolvida, essas questões devem ser avaliadas para determinar se as respostas oferecerão as informações necessárias para a tomada de decisão, para a compreensão de um problema ou para testar uma teoria" (2005, p.215), e considerando todas as orientações discutidas acima, propôs-se, com o objetivo de dar maior praticidade ao processo de formulação do questionário, um check list (quadro 1) com a listagem dos aspectos a serem considerados na elaboração e análise de questionários voltados para coletar dados para pesquisas de crenças.

O objetivo desse instrumento é servir como uma ferramenta prática de apoio em todas as fases da criação do questionário, isto é, sua abrangência deve possibilitar consultá-lo antes de se elaborar questões (orientações sobre adequação às características dos sujeitos), durante a criação (cuidados com aspectos de ordem, estrutura e apresentação) e depois (revisão de todos os passos). Além disso, como dissemos antes, pode ser utilizado também para analisar e revisar questionários considerados prontos para serem usados.

\section{CHECK LIST}

\section{ANTES DE ELABORAR QUESTÕES}

Definir:

Objetivos

População alvo

Conceitos

Tópicos

Tipo de administração do questionário

Método de análise de respostas

\section{ELABORAÇÃO DAS QUESTÕES}

Perguntas de abertura

Perguntas baseadas nos tópicos do questionário

Perguntas de classificação 


\begin{abstract}
APRESENTAÇÃO DAS QUESTÕES
Utilizar linguagem adequada aos respondentes

Usar perguntas breves

Evitar termos ambíguos

Evitar questões dominantes

Evitar questões múltiplas

Cuidar a ordem das questões

Evitar os possíveis efeitos de contexto
\end{abstract}

Avaliar questões do ponto de vista dos respondentes

Considerar os tipos de pergunta: abertas, fechadas

\title{
APRESENTAÇÃO DO QUESTIONÁRIO
}

Evitar separar uma questão em duas páginas

Definir:

Estrutura

Espaçamento

Organização

Criar instruções claras:

Introduzir e explicar como responder

Indicar quantas respostas são aceitáveis

Solicitar que o respondente responda sozinho

Destacar as instruções (negrito, itálico, sublinhado, etc.).

\section{PRÉ-TESTE}

Utilizar amostras de respondentes com características semelhantes às da população alvo

Aplicar em ambiente semelhante ao que será utilizado durante a pesquisa

Acrescentar questões de sondagem sobre cada parte do questionário

Repetir o pré-teste se necessário

Quadro 1. Check List 


\section{Considerações Finais}

A validade de uma investigação sobre crenças está diretamente relacionada à qualidade dos dados utilizados, porque a discussão dos resultados se assenta sobre as informações coletadas. Assim, é fundamental o cuidado com os instrumentos utilizados para a coleta de dados. Foi a partir desse conceito que decidimos aprofundar nossos conhecimentos sobre elaboração de questionários e, dessa forma, chegamos ao check list.

Ressaltamos a importância desse instrumento por sua utilidade não estar restrita a pesquisa que lhe deu origem, pelo contrário, pode ser usado em outras áreas que utilizem pesquisas qualitativas e, inclusive, ser adaptado para seryir de guia para elaboração de questionários de pesquisas quantitativas.

Porém, esse instrumento, embora tenha se mostrado eficiente, tem um caráter experimental podendo, ainda, sofrer ajustes.

\section{Referências Bibliográficas}

BARCELOS, A. M. F. Metodologia de Pesquisa das Crenças sobre Aprendizagem de Línguas: Estado da Arte. In: Revista Brasileira de Lingüística Aplicada, v. 1, n 1, p.71-92, 2001.

Crenças sobre aprendizagem de línguas, Lingüística Aplicada e ensino de línguas. In: Linguagem \& Ensino, v.7, p. 123-156, 2004.

Cognição de professores e alunos: tendências recentes na pesquisa de crenças sobre ensino e aprendizagem de línguas. p. 15-42 In: Crenças e ensino de línguas - foco no professor, no aluno e na formação de professores (org.) Barcelos, A. M. F. e Abrahão, M.H.V. Pontes Editores: Campinas, SP, 2006.

BARCELOS, A. M. F. Crenças sobre ensino e aprendizagem de línguas: Reflexões de uma década de pesquisa no Brasil. In: ALVAREZ, M. L. O.; SILVA, K. A. Linguística Aplicada: Múltiplos Olhares - Estudos em homenagem ao Professor Dr. José Carlos Paes de Almeida Filho, Campinas, SP: Pontes, p. 27-70, 2007. 
HAIR Jr., Joseph F.; BABIN, Barry; MONEY, Arthur H.; SAMOUEL, Phillip. Fundamentos de Métodos de Pesquisa em Administração. Porto Alegre: BOOKMAN, 2005.

LÜDKE, Menga; ANDRÉ, M.E.D.A. Pesquisa em educação: abordagens qualitativas. São Paulo, SP. Ed. EPU, 1986.

LUDWIG, A. C. W. Fundamentos e prática de Metodologia Científica. Petrópolis, RJ. Ed. VOZES, 2009.

NUNAN, D. Research Methods in Language Learning. Cambridge, CAMBRIDGE UNIVERSITY PRESS, 1997.

SILVA, K. A. Crenças no ensino-aprendizagem e na formação de professores de línguas: delimitando e atravessando fronteiras na Linguística Aplicada brasileira. In: SILVA, K. A. (Org) Crenças, Discursos \& Língua(gem): Volume I. Campinas, SP: Pontes Editores, 2010.

Artigo recebido em: 31.03.2012

Artigo aprovado em: 14.05 .2012 